\title{
ethic@ \\ POR QUE INTERPRETAR A TEORIA ÉTICA DE MILL COMO UM TIPO DE UTILITARISMO DE ATOS
}

\author{
WHY INTERPRET MILL'S ETHICAL THEORY AS A KIND OF \\ ACT-UTILITARIANISM
}

\section{FERNANDA BELO GONTIJO ${ }^{1}$}

(UFSC/Brasil)

\begin{abstract}
RESUMO
É de amplo conhecimento entre os eticistas que a teoria moral defendida por John Stuart Mill é o utilitarismo. Não é de comum acordo entre eles, no entanto, qual teria sido o tipo de utilitarismo defendido por este filósofo, se de atos ou de regras. Este artigo visa apresentar os fundamentos para essa disputa e defende que Mill é um utilitarista de atos.
\end{abstract}

Palavras-chave: Mill; utilitarismo de atos; utilitarismo de regras.

\begin{abstract}
It is widely known among ethicists that Mill's moral theory is utilitarianism. It is not a consensus, however, what is the kind of utilitarianism he actually defended, if an act- or rule-utilitarianism. This paper aims to present the grounds for such dispute and supports that Mill is an act-utilitarian.
\end{abstract}

Keywords: Mill; act-utilitarianism; rule-utilitarianism.

\section{Introdução}

John Stuart Mill é, sem sombra de dúvida, um dos eticistas mais influentes da história da filosofia. Sua defesa do utilitarismo é globalmente conhecida, e aparece como figura carimbada nos melhores cursos de ética ministrados ao redor do mundo. Um aspecto de sua teoria ética, no entanto, tem intrigado, já há algum tempo, os intérpretes de seu pensamento. A pergunta que eles se fazem gira em torno do tipo de teoria da correção moral que Mill teria efetivamente defendido. Afinal de contas, seria ele um utilitarista de atos ou de regras?

A distinção entre esses dois tipos de utilitarismo é recente, e apareceu, com tal nomenclatura, em 1959, com a publicação de Ethical Theory, de Richard Brandt. Mas o conteúdo que caracterizaria cada uma dessas duas teorias aparece desde antes, sendo encontrada, inclusive, uma 
defesa do utilitarismo de regras já na obra Passive Obedience (1712), de George Berkeley - embora obviamente não com este nome.

Mas, afinal de contas, o que, exatamente, distingue ambas as teorias utilitaristas? A resposta é simples. Os utilitaristas de atos defendem que uma ação particular é correta se ela promove certo montante (máximo ou satisfatório, conforme a teoria) de bem-estar geral imparcialmente considerado. Já os utilitaristas de regras, defendem que a ação é correta se ela estiver de acordo com uma regra cuja generalização, ou cujo o reconhecimento ou obediência pela maior parte da sociedade, promove certo montante (máximo ou satisfatório, conforme a teoria) de bem-estar geral imparcialmente considerado.

Em ambas as teorias existe lugar para as regras morais. A principal diferença quanto ao papel das regras nas duas teorias está no estatuto que as mesmas possuem dentro de cada um dos tipos de utilitarismo. No caso do utilitarismo de atos, as regras são consideradas, numa tradução literal da expressão inglesa, "regras de polegar" (rules of thumb), ou seja, regras práticas que expressam a experiência moral da humanidade quanto ao que conduz à promoção do bem. Essas regras podem ser dispensadas sempre que, numa situação particular, o abandono da regra gerar um montante maior - mesmo que apenas ligeiramente maior - de bem-estar geral do que de mal. Já no caso do utilitarismo de regras, as regras possuem um estatuto mais rígido, podendo ser quebradas somente em situações muito especiais, como quando o ganho de bem-estar que se adquire com a quebra da regra é imensamente maior do que a sua observância ou quando a quebra evita algum desastre (HOOKER, 2000). O importante aqui é que a quebra da regra não arrefeça a confiança das pessoas na capacidade da regra de gerar sanções.

A disputa acerca do tipo de teoria da correção moral defendida por Mill surgiu porque há, curiosamente, indícios nas obras do filósofo que fundamentam fortemente ambas as interpretações, a "de atos" e a "de regras". Do lado da primeira interpretação, temos como defensores: Roger Crisp (1997) ${ }^{2}$, David Brink (2013) e Piers Norris Turner (2015), dentre outros. Do lado da segunda, J. O. Urmson (1953), Wendy Donner (2009/2011) e Dale E. Miller (2010), dentre outros. O diagnóstico que se faz dessa ambiguidade dentro do utilitarismo de Mill é de que ele é devido ao fato de a distinção entre os dois tipos de teorias não ter sido vigente à sua época, tendo aparecido, como já foi mencionado, apenas no século XX. Conforme veremos a seguir, em certas passagens, Mill parece conceder um lugar mais proeminente às regras e ter uma concepção delas enquanto normas que podem ser quebradas apenas em situações especiais. Em outras, confere-Ihes um caráter provisório, além de fornecer uma ênfase 
decidida na importância da análise das situações particulares. Nas seções seguintes, veremos em mais detalhes como fundamentar cada uma dessas interpretações é possível, e como a interpretação "de atos" parece ser a mais adequada, já que o artigo argumentará a favor desta última interpretação. Para tanto, me valerei, sobretudo da tese de que a defesa de Mill em carta a John Venn, de $1872^{3}$, de "que o modo certo de testar as ações" é avaliá-las por suas consequências particulares fornece uma confissão explícita do tipo de teoria da correção moral que ele pensa ser satisfatória.

\section{Duas possibilidades de interpretação}

\section{A tendência da ação}

O artigo "The Interpretation of the Moral Philosophy of J. S. Mill" (1953), de J. O. Urmson, é considerado a fonte seminal da interpretação segundo a qual Mill teria defendido um tipo de utilitarismo de regras ${ }^{4}$. Urmson apresenta quatro citações principais da obra de Mill para fundamentar sua defesa da interpretação do utilitarismo de Mill como sendo do tipo de regras.

Um dos trechos mencionado por Urmson que se encontra entre os mais ambíguos, isto é, que permitem ambas as interpretações ("de atos" e "de regras"), é o seguinte:

O credo que aceita a utilidade, ou o Princípio da Maior Felicidade, como fundamento da moralidade, defende que as ações estão certas na medida em que tendem a promover a felicidade, erradas na medida em que tendem a promover o reverso da felicidade (MILL, UT, II, $\S 2^{5} ;$ grifos nossos) ${ }^{6}$.

Em geral, os intérpretes de Mill consideram que tal passagem consiste em um forte indício de que o filósofo seria um utilitarista de atos. Isso porque por "tendência das ações" eles entendem "tendência das ações particulares". Assim, uma ação particular estaria correta na medida em que tendesse a promover a felicidade; e estaria incorreta na medida que ela novamente entendida como uma ação particular - tendesse a produzir o reverso da felicidade. $O$ assassinato de um inocente em dada situação poderia ser considerado moralmente incorreto se o ato de tirar a vida de um inocente, na circunstância em questão, tivesse a tendência de produzir mais mal do que bem. Se, na situação particular, o mesmo tivesse a tendência contrária, poderia ser considerado moralmente correto. 
Urmson, no entanto, questiona a ênfase na tendência das ações nesses termos. Ele defende que existe uma maneira de considerá-las que escapa a tal interpretação. Se se aceitar que Mill está falando de ações como types (conceitos descritivos abstratos), como classes de atos, não como tokens (instâncias particulares de algo), uma interpretação do utilitarismo de Mill do tipo "de regras" torna-se possível (1953, p. 37). Isso porque o utilitarismo de regras propõe a existência de regras gerais como reguladoras da normatividade e supõe que as ações são julgadas muito mais como classes ou tipos de ações do que como instâncias particulares de agência. A consideração pelas ações particulares constituiria exceções às regras gerais e sua discordância excepcional com a regra não seria capaz de enfraquecê-la.

Para entender melhor o que tudo isso significa, considere que poderia ser o caso de alguém tomar uma dose maior de álcool e não sentir a excitação característica da bebida. Isso, no entanto, não desmentiria o fato de que o álcool, se tomado em certas proporções, é, em geral, capaz de causar excitação nas pessoas. Retomando o exemplo do assassinato, pode ser o caso que, em uma situação particular, esse ato tenda a produzir mais bem do que mal - quando, por exemplo, se tira a vida de um ditador sanguinário para libertar um país oprimido. Porém, isso não muda o fato de que, em geral, a tendência dos assassinatos é gerar muito mais mal do que bem, já que o ato implica em ceifar uma vida. Enquanto type, o assassinato é malévolo, ainda que, enquanto um token específico, ele possa não ser. 0 trecho abaixo do Utilitarismo (1863) de Mill parece constituir exatamente a defesa desse argumento:

De facto, no caso das abstinências - das coisas que as pessoas se abstêm de fazer devido a considerações morais, ainda que num determinado caso as consequências de a fazer pudessem ser benéficas - seria indigno um agente inteligente não estar consciente de que a ação pertence a uma classe de ações que, se geralmente fossem praticadas, geralmente seriam prejudiciais, e de que este é o fundamento da obrigação de se abster de a realizar (MILL, UT, II, §19; grifos nossos).

E ainda:

A porção das tendências de uma ação que pertencem às consequências não individualmente, mas como violação de uma regra geral, são tão certas e tão calculáveis quanto quaisquer outras consequências; elas apenas devem ser examinadas não no caso individual, mas em classes de casos (MILL, W, X, p. 181; tradução e grifos nossos). 
Neste último excerto, fica ainda mais patente a defesa de que, para Mill, se deve considerar a tendência das classes de ações e destas como subordinadas particularmente a regras gerais. Ora, o que parece ser isto senão o coração do utilitarismo de regras? Assim, do ponto de vista das três citações mencionadas, sobretudo, desta última, fica claro que uma interpretação "de regras" parece bastante plausível, já que parece haver uma ênfase decidida de Mill pela consideração das ações como classes e como sujeitas a regras gerais, e não como casos individuais.

Contudo, conforme já foi mencionado na "Introdução", o utilitarismo de atos também aceita a subordinação das ações a regras e pode perfeitamente acomodar a ideia de que as ações devem ser entendidas como classes de ações. Tudo depende de que tipo de utilitarismo de atos estamos falando. Se tivermos em mente um utilitarismo de atos simples e direto, sem maiores sofisticações, torna-se implausível a defesa de que Mill seria um utilitarista de atos. Porém, se tivermos em mente um utilitarismo de atos mais sofisticado, que confere certo estatuto às regras morais dentro da teoria, a última citação torna-se ambígua em termos interpretativos. Assim, para efetivamente entender se a defesa da tendência das ações enquanto classes de ações fundamenta um utilitarismo de atos ou de regras, é preciso estabelecer duas coisas: (i) qual é o estatuto que as regras ocupam dentro do utilitarismo de Mill e (ii) qual a interpretação do tipo "de atos" e qual a interpretação do tipo "de regras" podem ser atribuídas à sua teoria. Vejamos o que pode ser dito sobre este último tópico nas duas seções seguintes.

\section{Código vigente ou código ideal?}

Segundo Wendy Donner (2011, p. 80-85), existem pelo menos três tipos de utilitarismo de regras: (i) o da generalização utilitarista, (ii) o do código moral vigente e (iii) o do código moral ideal. O utilitarismo de regras da generalização utilitarista é o tipo de utilitarismo a que se chega ao fazer a pergunta sobre o que aconteceria se todos seguissem um determinado tipo de regra, se isso levaria ou não à promoção do bem-estar geral. Esse é um tipo rudimentar de utilitarismo e até pode-se afirmar que ele fundamenta um raciocínio que em alguma medida, acaba por ser adotado por todos os utilitaristas de regras. Uma passagem que indica que este pode ter sido o tipo de utilitarismo defendido por Mill é a penúltima citação supramencionada (seção anterior), a qual foca nas classes de ações que se fossem praticadas seriam geralmente prejudiciais. 
No entanto, apesar de tal passagem poder ser apontada como um indício claro da defesa de Mill do utilitarismo de regras da generalização utilitarista, há outros elementos de sua teoria que indicam uma versão do código moral. Em primeiro lugar, no parágrafo vinte e quatro do segundo capítulo de Utilitarismo, Mill afirma explicitamente que "o código ético aceite não tem qualquer autoridade divina" (grifo nosso). Sua crença explícita de que os agentes morais deveriam ser moralmente educados, e de que isso serviria de base para o seu progresso moral e o da sociedade, também indica que ele tinha uma concepção das regras morais como pertencentes a um código que deveria ser internalizado e ensinado a todos. Vejamos o que ele acreditava ser possível com a educação: "Mesmo a doença, o mais intratável dos inimigos, pode ver indefinidamente reduzida a sua dimensão graças a uma boa educação, tanto física como moral, e a um controlo apropriado das influências nocivas [...]" (MILL, UT, II, §14; grifos nossos). Conforme Mill, ainda, para alguém ser capaz de desfrutar, por exemplo, dos prazeres superiores seria preciso que esse indivíduo passasse pelos incentivos corretos para despertar em sua natureza tal disposição: "Na maior parte das naturezas, a capacidade para os sentimentos mais nobres é uma planta muito delicada, que morre facilmente não só devido a influências hostis, mas também à simples falta de alimento [...]" (MILL, UT, II, §7). Parte desses incentivos viriam através de determinados arranjos sociais, arranjos nos quais a internalização de um código de regras conducentes ao maior bem-estar geral seria fundamental.

Mas se o utilitarismo de Mill pode ser interpretado como uma versão "de regras" do código moral, esse código seria vigente ou ideal? Para Donner (2011, p. 84), Mill teria defendido o primeiro tipo de teoria. Já Brandt (1992, p. 119), pensava que ele teria defendido o segundo. Seja qual for o caso, em ambos,

a ênfase de Mill na educação e no desenvolvimento como estando essencialmente unidos à moralidade pode ser vista no sentido de fornecer as condições necessárias, a formação essencial e a inculcação, de modo a que as regras sejam interiorizadas e adoptadas pela maioria (DONNER, 2011, p. 82).

Os utilitaristas de regras do código moral vigente propõem que a correção moral de um ato depende de sua adequação a uma regra que está inserida dentro do código moral vigente na sociedade. Segundo Brandt (1992, p. 115; tradução nossa), o que torna essa teoria utilitarista é que "pensa-se que o que é relevante para uma decisão quando for para tentar mudar os códigos, instituições, etc. morais ou for para justificá-los, é a 
utilidade relativa do código, prática, etc.". Conforme a versão da teoria, o código pode ser o vigente da sociedade do indivíduo, ou o melhor código vigente entre todas as sociedades existentes, ou, até mesmo, o melhor código moral que já tenha sido vigente ao longo da história da humanidade. O importante é que, no caso de Mill, supondo que ele tenha defendido uma versão do código moral vigente, tal código não é estático. Ao contrário, para Mill, as regras podem ser constantemente aperfeiçoadas. Assim ele nos explica:

Os corolários do princípio da utilidade, tal como os preceitos de qualquer arte prática, admitem um melhoramento indefinido, e, num estado progressivo da mente humana, o seu melhoramento decorre continuamente (MILL, UT, II, §24; grifo nosso).

Ora, mas se este é o caso, será que não há por trás deste raciocínio uma concepção do código como sendo ideal? Se as regras podem sempre ser aperfeiçoadas, parece que existe já um padrão ideal de código guiando a seleção das regras do mesmo. Segundo Brandt (1992, p. 115; tradução nossa), no utilitarismo de regras do código moral ideal "é feita uma função de regras ideais em algum sentido". Mais robustamente, os utilitaristas de regras do código moral ideal propõem que a correção moral de um ato depende de sua adequação a uma regra que está inserida dentro de um código moral, o qual está justificado se promover o montante de bem-estar geral máximo ou satisfatório (a depender da versão da teoria) quando internalizado ou obedecido pela maioria da sociedade. De acordo com Donner (2011, p. 83), "a leitura do código moral ideal é a de que o código, no essencial, é todo o conjunto de regras que produziriam a maior felicidade se aceites e adoptadas pela maioria". Assim, desde que sejam as melhores possíveis, as regras do código podem estar vigentes ou nunca terem sido incorporadas ao código.

Para Donner (2011, p. 83), no entanto, o fato de as regras serem aperfeiçoáveis exclui a caracterização do código como ideal. Isso porque se elas podem ser aperfeiçoadas, significa que são imperfeitas e não se enquadram ainda no que venha a ser concebido como ideal. Todavia, é possível argumentar que o código ideal não é sinônimo de código perfeito, só é aquele que é maximamente eficiente para garantir o bem-estar geral, ainda que suas regras nem estejam operando ainda na sociedade. Além disso, a ideia de aperfeiçoamento parte, sem sombra de dúvida, de um ideal normativo, de um patamar que se almeja alcançar e que não está, pelo menos não ainda, inteiramente ao alcance de quem o deseja. Logo, uma 
concepção do código moral como sendo ideal se adequa bem ao que pensa Mill acerca do desenvolvimento das regras morais.

\section{Utilitarismo de atos simples ou sofisticado?}

Até aqui, vimos que se a teoria de Mill for interpretada como utilitarista de regras, parece mais adequado interpretá-la como um tipo e utilitarismo de regras do código moral ideal. Mas e se a interpretarmos como uma teoria utilitarista de atos - interpretação proposta neste artigo -, em qual tipo ela se enquadraria?

Conforme já mencionamos, é possível defender o utilitarismo de atos tanto em sua versão simples quanto na sua versão sofisticada. Para um utilitarista de atos simples, a ação correta é a que maximiza imparcialmente o bem-estar geral (este seria o chamado "princípio de utilidade"), sendo o cálculo de bem-estar realizado a cada momento da ação particular No caso desta teoria, nenhum outro princípio ou regra moral diferente do princípio de utilidade guia a vida prática das pessoas. A pergunta que esse tipo de utilitarista faz é: "Esta ação específica, realizada nesse momento específico, maximiza imparcialmente o bem-estar geral?". Se sim, então a ação é, ao mesmo tempo, a ação correta e o guia das decisões morais do agente. Se não, então ela é incorreta e incapaz de guiar a vida prática.

Já no caso do utilitarismo de atos sofisticado, existe um raciocínio em dois níveis. Por um lado, utiliza-se o princípio de utilidade para avaliar se a ação particular considerada é correta, ou seja, ele é o critério de correção. Por outro, vale-se de princípios do senso comum, motivos, traços de caráter, etc. para saber qual é a decisão que se deve tomar em determinada circunstância. O princípio de utilidade é, então, o definidor da correção moral, mas não é, ao mesmo tempo, o procedimento de decisão da vida dos agentes.

Tendo considerado essas duas versões da teoria, e supondo que Mill teria sido um utilitarista de atos, fica a questão de saber qual dessas duas variantes ele teria defendido. Retomar a passagem referente aos corolários e generalizações intermédias e trazer à baila a citação que trata do que Mill chama "princípios secundários" ajuda a esclarecer qual teria sido a versão de utilitarismo de atos defendida por ele - tudo leva a crer que é um tipo de utilitarismo de atos sofisticado. Ambas as passagens são apresentadas abaixo:

Os corolários do princípio de utilidade [...] admitem melhoramento indefinido, e, num estado progressivo da mente humana, o seu melhoramento decorre continuamente. Contudo, considerar que as regras morais não se podem 
provar é uma coisa; outra coisa é passar por cima das generalizações intermédias e fazer um esforço para testar diretamente cada ação individual através do primeiro princípio (MILL, UT, II, §24; grifos nossos).

E, na sequência:

É estranho pensar que o reconhecimento de um primeiro princípio é inconsistente com a admissão de princípios secundários. [...] Seja qual for o princípio que adoptemos como princípio fundamental da moralidade, precisamos de princípios subordinados através dos quais o possamos aplicar; a impossibilidade de passarmos sem eles, sendo comum a todos os sistemas, não pode proporcionar qualquer argumento contra um em particular. Mas argumentar seriamente como se não pudéssemos ter quaisquer desses princípios secundários, e como se a humanidade tivesse permanecido até agora, e vá permanecer sempre, sem retirar quaisquer conclusões gerais da experiência da vida humana, é, penso, atingir um nível de absurdidade jamais atingido através da controvérsia filosófica (MILL, UT, II, §24; grifos nossos).

Na primeira citação, dois conceitos são chaves: o de "corolários" e o de "generalizações intermédias". Os corolários mencionados por Mill são os princípios morais que se seguem de se aceitar o princípio da utilidade, tais quais como: "Matar é errado", "Mentir é errado", etc.; isto é, todos os princípios que se internalizados ou obedecidos levam ao maior bem-estar geral. As generalizações intermédias são as regras gerais que os agentes morais devem adotar para maximizar o bem, em vez de considerar cada ação particularmente.

Na segunda citação, o conceito-chave é o de "princípios secundários", que seriam idênticos aos corolários do princípio de utilidade. Para Mill, o princípio primeiro, isto é, o princípio normativo fundamental, é o princípio de utilidade. Porém, como guia da vida prática, ele não seria o único. Neste ponto, Mill deixa evidente seu empirismo e defende que a experiência da humanidade já teria selecionado um conjunto de princípios diferentes do de utilidade, os quais, se internalizados ou seguidos, conduziriam à maximização do bem-estar geral. É a esses princípios que Mill chama "corolários" ou "princípios secundários" ou, ainda, "princípios subordinados". As regras morais que se seguiriam desses princípios seriam as generalizações intermédias. 
Para que a promoção do bem-estar fosse mais eficiente, seriam esses princípios e regras que deveriam guiar o raciocínio e as decisões morais na maior parte do tempo. Nenhum agente moral humano teria tempo suficiente ou seria cognitivamente capaz de calcular todas as consequências de cada ação em particular, sempre. Seguir tais princípios e regras seria uma maneira de aproveitar os resultados extraídos dos cálculos das consequências das ações já realizados ao longo de toda a história da humanidade. Nesse contexto, o princípio de utilidade cumpriria a função de solucionar casos de conflitos entre os princípios secundários, ou seja, em situações nas quais dois deles fossem notoriamente conducentes ao maior bem. Segundo Mill,

aqueles que adotam a utilidade como padrão raramente podem aplicá-lo verdadeiramente, exceto através dos princípios secundários; aqueles que o rejeitam, não fazem mais do que elevar aqueles princípios secundários a primeiros princípios. É quando dois ou mais dos princípios secundários conflitam que um apelo direto ao princípio primeiro se torna necessário; e então tem início a importância prática da controvérsia utilitarista [...]. (MILL, B, X, p. 110-111; tradução e grifos nossos).

Urmson quer nos fazer acreditar que a defesa de Mill de tais tipos de princípios e generalizações intermédias constituiriam uma defesa patente do utilitarismo de regras (os trechos referentes a esses conceitos seriam as duas outras citações que provariam a correção de sua interpretação). Ele afirma que as passagens supramencionadas deixam claro que, para Mill, as regras "são uma parte essencial do raciocínio moral" (URMSON, 1953, p. 36), constituindo mais do que simplesmente guias práticos da ação moral. Mas será isto verdade? Para responder a esta questão é preciso, passar, então, à análise propriamente dita do estatuto das regras morais na teoria utilitarista de Mill.

\section{Atos e regras: o estatuto das regras morais}

Conforme foi possível perceber até este momento, não se pode negar o papel relevante das regras morais dentro da teoria de Mill. Consoante o que ele próprio assere, "pelo menos em certas descrições de atos, a moralidade constitui a simples observância a uma regra" (MILL, SL, VIII, p. 1154; tradução nossa). Todavia, fica ainda uma questão: qual seria o estatuto de tais regras dentro de sua teoria? Deveriam elas ser o padrão de 
correção moral? Ou constituiriam apenas o procedimento de decisão? Tudo muda dentro da teoria conforme a resposta dada a essas questões.

Uma das teses, a defendida pelos intérpretes da versão "de regras", é a de que as regras morais teriam um estatuto suficientemente elevado para serem quebradas somente em circunstâncias muito especiais. É exatamente essa tese que é defendida no trecho a seguir:

[...] Ainda há a necessidade de que alguma regra, de uma natureza simples 0 bastante para ser facilmente compreendida e relembrada, não deva apenas ser estabelecida como guia, mas universalmente observada, para que as várias pessoas concernidas possam saber o que esperar $[\ldots]$.

Tal, por exemplo, é a regra de dizer a verdade [...]. É óbvio que embora existam em muitos casos nos quais um desvio da regra no caso particular produziria mais bem do que mal, é necessário, para a segurança geral, que ou as regras sejam inflexivelmente observadas ou que a licença de desviar delas $[. .$.$] seja confinada a classes definidas de casos, e que$ estes sejam de uma natureza bem peculiar e extrema (MILL, $S L$, VIII, p. 1154-1155; tradução e grifos nossos).

Veja como, muito claramente, Mill defende que as regras morais devem ser (i) universais e (ii) inflexivelmente observadas, sendo o contrário permitido apenas em circunstâncias muito particulares e pré-definidas dentro do código moral7. A justificativa para isso é bem simples: as pessoas devem saber o que esperar umas das outras dentro de uma comunidade moral. Se sei que as pessoas podem mentir a qualquer momento, nunca confiarei no que quer que seja que alguém me diga. Se sei que não há uma proibição que suprime a agressão do meu vizinho em direção a mim, na maior parte das circunstâncias, estarei em estado de alerta todo o tempo sem saber se, agora ou no futuro, devo esperar por uma violação de minha integridade física. Por conseguinte, não é possível esperar que as pessoas atingirão o maior bem-estar em situações desse tipo, pois se encontrarão sempre em um estado de guerra de todos contra todos. Assim, parece defender Mill, para promover o maior bem-estar geral é preciso conferir às regras morais um estatuto mais forte e elevado.

No entanto, se observarmos as passagens apresentadas abaixo, é fácil perceber como esta visão do estatuto das regras morais dentro do utilitarismo de Mill não é definitiva. Elas apontam para a defesa de outra tese, a de que as regras morais teriam um estatuto mais fraco, consistindo 
apenas em guias práticos para a vida, sendo de autoridade meramente provisória. Considere esta primeira:

Por um agente prático sábio, portanto, as regras de conduta serão consideradas exclusivamente como provisórias. Tendo sido fabricadas para a maior parte dos casos, ou ao menos para aqueles de ocorrência mais ordinária, elas apontam para o modo no qual será menos perigoso agir, onde o tempo ou os meios para analisar as circunstâncias do caso não existem, ou onde não podemos confiar em nosso juízo em estimá-las. Mas elas não substituem, de modo algum, a propriedade de passar (quando as circunstâncias o permitem) pelo requisito de processo científico para extrair uma regra dos dados do caso particular diante de nós (MILL, SL, VIII, p. 946; tradução e grifos nossos).

Nessa passagem, diferente do que ocorre no trecho citado anteriormente, fica claro que, para Mill, as regras morais servem apenas de guia provisório em situações como: quando elas fornecem uma segurança para o agente moral em termos de danos que ele pode evitar para si ou para os outros; quando não há tempo para pesar todos os prós e contras de agir de determinada maneira no caso particular; ou quando, por alguma razão, não nos encontramos em posição de confiar em nosso próprio juízo - por exemplo, quando estamos sob estresse. O agente moral sábio, dado a sua educação e treino morais, saberá quando distinguir as situações nas quais há a necessidade de seguir uma regra e quando será preciso aplicar o princípio de utilidade diretamente, tendo em mente, que, em vez de aplicar a regra automaticamente, é preferível considerar as peculiaridades do caso particular para decidir como agir. Isso porque a regra não substitui a análise "científica" do caso particular, isto é, a investigação detida das particularidades do caso e dos prós e contras de cada possibilidade de curso de ação.

É claro que alguém poderia argumentar que, ao falar de uma "análise científica" do caso particular, Mill pretenderia defender uma visão da moralidade enquanto ciência do comportamento humano, da qual seria possível extrair regras mais gerais, que seriam as regras morais. Contudo, a divisão entre ciência e arte dentro do pensamento de Mill ajuda a esclarecer que este provavelmente não foi o caso. O campo da arte é delegado ao estabelecimento de padrões e regras mais gerais (ele é prescritivo) - e as regras morais seriam extraídas dentro deste contexto enquanto o campo da ciência estaria ligado à descrição (não à prescrição) da realidade (EGGLESTON; MILLER \& WEINSTEIN, 2011, p. 4). Neste último 
campo, estuda-se os fenômenos - também os fenômenos morais - como efeitos de certas causas e um dos papéis da ciência seria investigar esta relação (MILL, SL, VIII, p. 944-945).

A posição centrada na análise dos casos particulares é reforçada ainda em duas outras citações, as quais são apresentadas na sequência. Considere este segundo trecho - pouco citado nos trabalhos mais proeminentes sobre Mill:

Sem dúvida, nas complexidades infinitas dos negócios humanos, qualquer teorema geral com o qual um homem sábio irá se preocupar, deve ser tomado como uma simples aproximação da verdade; [...]. Nenhum homem sábio, portanto, irá confiar apenas no teorema, deixando de olhar para as especificidades do caso em questão, e ver quais características dele [do caso] podem ser extraídas de qualquer teorema, ou podem ser incluídas em mais de um [teorema]. [...]. Princípios gerais não são pensados para dispensar o pensamento e o exame, mas para nos ajudar a pensar e a examinar. Quando o próprio objeto está fora de alcance, e não podemos examiná-lo, devemos seguir princípios gerais, pois, ao fazê-lo, provavelmente não incorreremos em erro, e, provavelmente, não incorreremos em um grande erro, como se flutuássemos em um oceano sem limite de simples conjectura; mas quando não somos levados a especular, quando temos os meios e as ferramentas para observar, princípios gerais não são mais do que um auxílio em direção a um melhor uso desses meios e ferramentas (MILL, 1965, p. 200).

Observe, primeiramente, que, na passagem acima, Mill põe em questão qualquer princípio geral como critério isolado de descoberta de verdades e guia da ação moral. Isso nos leva a crer que mesmo o princípio de utilidade, embora seja um princípio fundamental, deve ser utilizado em conjunção com o aprendizado moral do agente para guiar decisões no âmbito da vida prática. E se esse é o caso com o princípio de utilidade, o que não dizer, então, dos princípios secundários? Eles, de certa maneira, também são princípios gerais, embora não sejam equivalentes a qualquer princípio primeiro. Eles servem como critério de agrupamento dos atos dentro de classes mais gerais. Contudo, conforme fica claro na passagem supramencionada, eles não são a última palavra para muitas decisões morais do agente. Para chegar até elas, em várias circunstâncias, é preciso aplicá-los às especificidades de cada caso. Todavia, proceder desse modo, 
nem sempre é possível. Assim, quando não há meios de analisar os casos particulares, os princípios secundários são excelentes guias de ação; eles não só nos ajudam a chegar à melhor decisão moral, como nos ajudam a não estarmos redondamente enganados quanto a ela. Ao final do trecho citado, no entanto, Mill insiste que tais princípios não substituem "o pensamento e o exame", isto é, a análise detida das singularidades do caso em questão. Havendo "os meios e as ferramentas" (tempo, acuidade emocional, acuidade intelectual, capacidade preditiva, etc.) para realizá-la, ela não deve ser descartada. Considere como tudo isso põe em xeque a ideia de que regras oriundas de princípios mais gerais têm um estatuto forte dentro do utilitarismo de Mill. Observe, assim, como todas essas afirmações coadunam exatamente com uma leitura utilitarista de atos sofisticado da teoria ética de Mill.

Contudo, as duas passagens citadas acima, por si, não sustentam tal interpretação, pois, conforme foi possível observar até aqui, há outras que sustentam de maneira igualmente forte a interpretação "de regras". Para poder, de fato, defender uma interpretação "de atos" é preciso encontrar, nas obras de Mill, um trecho que deixe claro que o critério de correção moral consiste em analisar as consequências dos casos particulares. Ora, se esse é o caso, eis que ele o defende no trecho citado abaixo:

o modo certo de testar ações por meio de suas consequências é testá-las pelas consequências naturais da ação particular, e não por meio daquelas que se verificariam caso todos fizessem o mesmo. Mas, na maior parte dos casos, a consideração pelo que aconteceria se todos fizessem o mesmo é o único meio que temos de descobrir a tendência da ação no caso particular (MILL, LJV, 17, p. 1881, tradução e grifos nossos).

Este trecho é fundamental para uma defesa do utilitarismo de Mill como sendo do tipo de atos. A afirmação de que existe um modo certo de testar as ações e de que este modo deve centrar-se nas consequências da ação particular dissipa qualquer dúvida acerca do que Mill pensava ser o modo adequado de verificar a correção moral de uma ação. Claro que nem sempre será possível chegar à conclusão de qual é a ação correta por meio de considerações mais diretas sobre a ação particular. Nesses casos, será preciso julgar a ação à maneira do utilitarismo de regras da generalização utilitarista. No entanto, observe que esse não é exatamente o modo de certo de verificar a correção moral da ação. Ele é apenas uma concessão feita por Mill dadas as dificuldades práticas que podem se delinear quando da avaliação moral feita pelos agentes. Havendo, todavia, circunstâncias 
favoráveis para se obter o conhecimento moral, é o que ocorre no caso particular que importa.

\section{O §14 do quinto capítulo de Utilitarismo}

Para Urmson, há ainda uma quarta passagem dentro das obras de Mill que prova que ele seria um utilitarista de regras. O trecho consiste no décimo quarto parágrafo do quinto capítulo de Utilitarismo. Cito exatamente os excertos do parágrafo considerados por Urmson:

Penso que aquilo que vimos até aqui constitui, dentro dos seus limites, uma descrição verdadeira da origem e do crescimento progressivo da ideia de justiça. Mas temos de observar que, por agora, a descrição nada inclui que designa essa obrigação da obrigação moral em geral, pois a verdade é que a ideia de sanção penal, que é a essência da lei, faz parte não só da concepção de injustiça, mas também da concepção geral daquilo que é errado. Não consideramos uma coisa errada caso não julguemos que uma pessoa deve ser punida de uma maneira ou de outra por a ter feito - se não pela lei, pela opinião de seus semelhantes; se não pela opinião, pelas repreensões da sua própria consciência. Este parece ser o verdadeiro ponto decisivo da distinção entre a moralidade e a simples conveniência. Em qualquer uma das suas formas, a noção de dever inclui a ideia de que uma pessoa pode ser legitimamente obrigada a cumpri-lo. O dever é algo que pode ser exigido de uma pessoa do mesmo modo que se exige o pagamento de uma dívida - se não pensamos que the pode ser exigido, não dizemos que é o seu dever. [...]. Há outras coisas que, pelo contrário, embora desejemos que as pessoas as façam (gostamos delas ou admiramo-las por as fazerem, e talvez não gostemos delas ou as desprezemos por as não fazerem), admitimos que não estão obrigadas a fazê-las. Esses não são casos de obrigação moral. Não culpamos as pessoas por não fazerem essas coisas, isto é, não pensamos que elas são objetos apropriados de castigo. [...] Mas penso que não há dúvida que esta distinção está na base das noções do certo e do errado, isto é, que consideramos uma conduta errada quando pensamos que uma pessoa deve ser castigada por ela, e que usamos outro termo negativo ou depreciativo caso não pensemos isso; e dizemos que seria certo fazer tal e tal coisa, se desejamos que a pessoa em questão seja compelida a fazê-la, mas dizemos apenas que isso seria desejável ou louvável, se desejamos que essa pessoa seja só 
persuadida ou incentivada a agir dessa maneira (MILL, UT, V, $\S 14)$.

Grosso modo, o que Mill defende na passagem acima é uma concepção na qual se chega ao conhecimento do que é incorreto a partir da ideia de sanção ou punição. Se é algo é passível de sanção, é obviamente incorreto. Se algo, por outro lado, é correto, ou seja, é um dever, é algo que tem de ser cumprido pelos agentes morais. Acreditamos que, quando se trata desses atos, as pessoas devem ser compelidas a realizá-los. À maneira da situação de um devedor, o agente moral pode ser cobrado caso se recuse a segui-los. Contudo, há ainda os atos meramente louváveis, os quais embora sejam bons, não são exatamente um dever. Devemos incentivar as pessoas a realizá-los, mas eles não são passíveis de sanção quando não são cumpridos. Esses são os atos contemporaneamente denominados "supererrogatórios". Segundo Urmson (1953, p. 37), na passagem acima, Mill deixa muito claro que, "na sua visão, o certo e o errado são derivados de regras morais". O ponto de Urmson, defendido também por David Lyons (1976), é que uma concepção de correção tal como a de Mill, que envolve a aplicação de sanções internas e externas quando da realização do que é incorreto, supõe a internalização de certas regras morais em relação às quais todos os agentes podem ser repreendidos, sobretudo por sua própria consciência, caso não venham a Ihe obedecer. Ora, esse modo de abordar a aplicação de sanções é característico do utilitarismo de regras do código moral, de modo que uma leitura da teoria de Mill nesses termos parece perfeitamente aceitável.

Contudo, por outro lado, nada do que Mill afirma na passagem acima, exclui uma interpretação "de atos" de seu utilitarismo. Basta considerar que a obrigação fundamental do agente moral, segundo Mill, é maximizar imparcialmente o bem-estar geral. Desse modo, qualquer aplicação de sanções (internas ou externas) deve se dirigir aos casos nos quais o agente se nega a fazê-lo. E isso se aplica quando uma regra moral - seja ela uma regra prática, ou uma generalização ou uma regra de determinado código - é quebrada, assim como quando o ato particular, considerado em si mesmo, não resulta em tal objetivo.

O fato de Mill propor a existência de atos supererrogatórios, conforme Dale E. Miller (2010), também contaria a favor de uma leitura "de regras" do utilitarismo milliano. Há outro trecho presente na obra de Mill que reforça a ideia de que ele prevê, em seu pensamento, a existência de atos supererrogatórios. O excerto é o que segue:

Há um padrão de altruísmo em relação ao qual todos deveriam ser requisitados a cumprir e um grau além em que 
isso não é obrigatório, mas meritório. É da incumbência de cada um restringir a busca de seus objetivos pessoais dentro de um limite consistente como interesse essencial dos outros. O que sejam esses limites, cabe à ciência da ética determinar; e manter todos os indivíduos [...] dentro deles é o ofício próprio do castigo e da culpa moral. Se além de cumprir esta obrigação, as pessoas fazem do bem de outras um objeto direto de esforços desinteressados, adiando ou sacrificandoIhe mesmo os prazeres pessoais inocentes, merecem gratidão e honra, sendo objetos dignos de louvor moral. Desde que não sejam de modo nenhum obrigados a ter esta conduta por alguma pressão exterior, nenhum esforço é demasiado; porém, uma condição necessária é a espontaneidade. [...] 0 objetivo deve ser estimular os serviços à humanidade mediante uma recompensa natural e não tornar a prossecução do nosso próprio bem numa tarefa impossível de outro modo, castigando-a com as críticas dos outros ou da nossa própria consciência (MILL, $A P, \mathrm{X}$, p. 337-338; grifos nossos).

Nessa passagem, Mill deixa bem claro que ele acredita haver um conjunto de atos obrigatórios, os quais deveriam beneficiar outras pessoas, e outro conjunto de atos que também beneficiam as pessoas, mas não seriam obrigatórios. Mill chama a estes últimos atos "meritórios" - no contexto, fica claro que ele está se referindo aos atos supererrogatórios. No caso dos atos do primeiro grupo, a sua desobediência a eles merece "castigo e culpa moral". No caso dos atos do segundo grupo, devemos àqueles que os praticam "gratidão e honra", não Ihes sendo aplicáveis o castigo externo e a reprovação da consciência do agente quando do seu descumprimento. Conforme reforça Mill, uma condição necessária dos atos supererrogatórios é justamente a espontaneidade.

O argumento de Miller para defender a interpretação "de regras" parte das passagens que provam que Mill admitia a existência de supererrogação e insiste que o utilitarismo de atos não é compatível com a existência de atos supererrogatórios porque estes seriam de um valor moral superior ao dos atos moralmente requeridos. Dado que o utilitarismo de atos requer a perfeição, isto é, envolve promover o maior montante de bem, todo ato requerido já seria de máximo valor moral. Desse modo, seria impossível acomodar a supererrogação.

Contudo, a teoria de Mill, enquanto utilitarista de atos sofisticada, prevê a promoção indireta do maior bem-estar geral imparcial através da obediência a regras práticas oriundas dos princípios secundários. O que 
significa que os atos particulares do agente não precisam, eles próprios, ao menos não todo o tempo, serem maximizadores do bem. Assim, há circunstâncias nas quais a realização de atos particulares maximizadores do bem-estar geral pode ser supererrogatória, em vez de obrigatória. A maximização seria obrigatória somente quando a aplicação direta do princípio de utilidade fosse inevitável, em vez de opcional. Logo, mesmo no contexto de um utilitarismo de atos sofisticado a supererrogação seria possível, o que significa que a interpretação "de atos" do utilitarismo de Mill é ainda plausível.

\section{Considerações finais}

O objetivo do artigo não foi fornecer a palavra final acerca da interpretação em torno do tipo de utilitarismo defendido por Mill. Contudo, houve a intenção de mostrar como há passagens que ou são negligenciadas dentro da literatura sobre o problema ou não recebem a detida análise que merecem. No contexto da discussão apresentada, há de se considerar que, afinal de contas, a teoria de Mill pode talvez não ser adequadamente enquadrada em apenas uma das duas posições mencionadas, o utilitarismo de atos ou o utilitarismo de regras. É possível, que ora o filósofo tenha pensado como um utilitarista do primeiro tipo, ora tenha pensado como um utilitarista do segundo. Talvez o próprio Mill estivesse incerto quanto a qual tipo de posição (ainda que a nomenclatura não fosse vigente à sua época) fosse a mais plausível de ser defendida e, por isso, oscilasse entre ora defender um tipo, ora defender o outro. Fica, então, o convite a outros intérpretes brasileiros para ampliarem a discussão em torno do tópico com o objetivo de se alcançar em nosso país uma visão mais acertada da teoria milliana. 


\section{Notas}

1 Licenciada em Filosofia pela Universidade Federal de São João del-Rei (2007) com especialização Lato Sensu em Filosofia pela Universidade Federal de Ouro Preto (2015), Mestrado em filosofia pela Universidade Federal do Paraná (2013) e Doutorado em filosofia pela Universidade Federal de Santa Catarina (UFSC, 2019). ORCID-iD: https://orcid.org/0000-0002-7044-1640; e-mail: fernanda.belo.gontijo@gmail.com

2 Crisp (1997, p. 105-112) defende uma interpretação utilitarista de atos, mas deste como sendo de múltiplos níveis (multi-level) de pensamento moral. Para Crisp, o utilitarismo de atos de Mill seria aquele no qual o princípio da utilidade é o critério de correção e a moralidade do senso comum é o procedimento de decisão. No dia a dia, deveríamos seguir o nível de pensamento moral no qual se obedece às regras da moralidade do senso comum que conduzem ao maior bemestar geral. Em situações especiais, deveríamos seguir outro nível de pensamento moral, seguindo diretamente o princípio de utilidade.

${ }^{3}$ Retornaremos a este ponto no devido momento.

${ }^{4}$ Neste artigo, Urmson não coloca a discussão exatamente nesses termos, pois essa nomenclatura só viria a aparecer em 1959; mas mesmo uma leitura rápida do texto deixa evidente que a interpretação proposta por ele é justamente esta.

${ }^{5}$ As obras de Mill serão citadas seguindo os respectivos formatos: 1) para Utilitarismo: AUTOR, ABREVIAÇÃO, capítulo, parágrafo; 2) outras obras: AUTOR, $A B R E V I A C ̧ \tilde{A} O$, volume das obras completas, página. Siglas: AP: Auguste Comte and Positivism; B: Bentham; LJV: Letter to John Venn; SL: A System of Logic; UT: Utilitarismo; W: Whewell on Moral Philosophy.

${ }^{6}$ A ideia de que ações são corretas ou incorretas conforme a sua tendência para gerar felicidade ou infelicidade é denominada "tese da proporcionalidade".

${ }^{7}$ Ver também: Mill (UT, II, §23). 


\section{Referências bibliográficas}

BERKELEY, George. Passive obedience: or, the Christian doctrine of not resisting the supreme power, proved and vindicated ... In a discourse deliver'd at the College-chapel. London: H. Clements, 1712.

BRANDT, R. B. Ethical Theory. Englewood Cliffs: Prentice-Hall, 1959.

BRANDT, R. B. Morality, Utilitarianism, and Rights. New York: Cambridge University Press, 1992.

BRINK, David. Mill's Progressive Principles. Oxford: Clarendon Press, 2013.

CRISP, Roger. Routledge Philosophy Guidebook to Mill on Utilitarianism. London: Routledge, 1997.

DONNER, W.; FUMERTON, R. 2009. John Stuart Mill. Lisboa: Edições 70, 2011.

EGgLESTON, B; MILLER, D. E; WEINSTEIN, D. John Stuart Mill and The Art of Life. Oxford: Oxford University Press, 2011.

HOOKER, B. Ideal Code, Real World: a rule-consequentialist theory of morality, Oxford: Oxford University Press, 2000.

MILL, J. S. 1838. Bentham. In: ROBSON, J. M. (Ed.). Collected Works of John Stuart Mill. Toronto: University of Toronto Press, 1969. Vol. X, p. 110111.

MILL, J. S. 1843. A System of Logic. In: ROBSON, J. M. (Ed.). Collected Works of John Stuart Mill. Toronto: University of Toronto Press, 1981. Vol. VIII, p. 944-945; 946; 1154; 1154-1155.

MILL, J. S. 1852. Whewell on Moral Philosophy. In: ROBSON, J. M. (Ed.). Collected Works of John Stuart Mill. Toronto: University of Toronto Press, 1969. Vol. X, p. 181.

MILL, J. S. 1865. Auguste Comte and Positivism. In: ROBSON, J. M. (Ed.). Collected Works of John Stuart Mill. Toronto: University of Toronto Press, 1969. Vol. X, p. 337-338. 
MILL, J. S. 1872. Letter to John Venn. In: ROBSON, J. M. (Ed.). Collected Works of John Stuart Mill. Toronto: University of Toronto Press, 1972. Vol. 17 , p. 1881-1882.

MILL, J. S. Carlyle's French Revolution. In: SCHNEEWIND, J. B. (Ed.). Mill's Essays on Literature and Society. Ed., NY: The Macmillan Company, 1965.

MILL, J. S. Utilitarismo. Porto: Porto, 2005.

MILLER, Dale E. John Stuart Mill: moral, social and political thought. Cambridge: Polity, 2010.

TURNER, Piers Norris. Rules and Right in Mill. Journal of the History of Philosophy, v. 53, n. 4, p. 723-745, 2015.

URMSON, J. O. The Interpretation of the Moral Philosophy of J. S. Mill. Philosophical Quarterly, v. 10, p. 33-39, 1953. 